\title{
Uma análise dos livros didáticos no ensino de conceitos de acidez para estudantes de 16 a 18 anos de idade
}

\author{
John Oversby*
}

\section{Introdução}

Como exemplo de transformações químicas, a acidez é um conceito estudado por alunos principiantes em disciplinas de química, sendo ampliado de várias formas conforme a aprendizagem se processa. Em níveis compatíveis com os dos livros didáticos nesta pesquisa, abordagens quantitativas são adotadas, enquanto modelos mais qualitativos são oferecidos aos estudantes universitários. A razão por trás da constituição de diferentes modelos raramente é explicitada aos estudantes, sendo possível que isto leve a dúvidas sobre qual poderia ser o melhor modelo. Em termos de acidez, a idéia da existência de diferentes modelos, cada um com seu valor em contextos diferentes, é mais satisfatória do que uma progressão hierárquica. Ao invés da progressão na qual o professor opta por um modelo com maior poder exploratório, uma alternativa na qual o professor escolhe um dado modelo como sendo mais adequado para um propósito particular, em função de seus potenciais e de suas limitações, parece ser a proposta mais apropriada.

* Ph. D., Escola de Educação Reading University, Reino Unido.

Trad.: Dra. Adélia Sílvia Angeli Teixeira de Paula, Departamento de Química, da Universidade Federal do Paraná, Curitiba, Brasil. 


\section{As idéias sobre acidez demonstradas pelos estudantes}

O processo de desenvolvimento da compreensão de ácidos é longo nas escolas. Na Inglaterra e no País de Gales, as crianças se tornam cientes do significado atribuído aos ácidos, tais como seu sabor azedo e sua capacidade de corrosão ("ou de queimar") de diversos materiais, no ensino fundamental, isto é, em torno da idade de 11 anos. Carr (1984) sugeriu que a noção que as crianças possuem sobre ácidos se origina de experiências cotidianas, tais como testar alimentos ácidos, e também de histórias e propagandas apresentadas na mídia. A noção de que ácidos "queimam" ou corróem materiais ainda é a principal idéia dos alunos de 15 anos de idade entrevistados por Hand e Treagust (1988). Os autores verificaram que, extraordinariamente, estas percepções continuam estáveis para um terço destes alunos, mesmo após intervenções dinâmicas de estratégias de ensino visando o desafio e a ampliação dessas noções. Hand (1989), testando estudantes de 17 anos, notou que os alunos ainda apresentavam problemas nas definições de "ácidos" e no conhecimento das diversas maneiras de se testar a acidez de uma substância. Carr (1984) apontou que existem vários modelos de ácidos usados no ensino de ciências e que os professores não os tornam explícitos aos alunos. Ross e Munby (1991) usaram testes para mapear a compreensão sobre ácidos em um estudo da capacidade de estudantes de 17 anos. Os autores constataram noções equivocadas sobre os produtos de neutralização, as propriedades dos ácidos, a natureza dos íons formados pelos ácidos (que foi pensado como sendo o íon hidróxido), e o $\mathrm{pH}$ relativo em ácidos fortes e fracos. Cros e colaboradores (1986), em uma pesquisa com estudantes universitários do $1^{\circ}$ ano, observaram que os alunos apresentavam uma capacidade limitada de dar exemplos de ácidos e bases, bem como de ácidos fortes e fracos. Schmidt (1991) verificou que a palavra neutralização foi interpretada por estudantes de nível médio na Alemanha como a posição (ou o ponto) onde a solução não é ácida nem básica, sendo mais propriamente um processo de movimento em direção a tal ponto. Em um trabalho mais recente, Schmidt (1991) investigou a idéia de ácidos e bases conjugados, notando uma confusão significativa sobre este assunto. 


\section{Fenômenos que podem ser explicados por modelos de ácidos}

Em níveis mais simples, a compreensão de uma reação química torna-se mais fácil através do reconhecimento de similaridades em um determinado grupo de eventos. A classificação de compostos baseada em características de comportamento é muitas vezes a primeira etapa na compreensão e reconhecimento de substâncias ácidas. O sabor, as reações com rochas básicas, as reações com alguns metais e com substâncias indicadoras foram parte de um desenvolvimento histórico e é desta maneira que o "ácido" é introduzido nas escolas. Químicos tentam compreender o ácido refletindo sobre sua composição, considerando-os como óxidos de não-metais. $\mathrm{O}$ reconhecimento do papel da água na produção de soluções com caráter ácido foi uma das contribuições da criação da idéia de que ácidos contêm hidrogênio. $\mathrm{O}$ advento da pesquisa baseada em fenômenos de condutividade levaram diretamente ao conceito de ácidos produzindo íons hidrogênio em solução. Este tipo de fenômeno, o qual levou ao modelo de Brönsted-Lowry, baseou-se na percepção de que a reação entre amônia e cloreto de hidrogênio em fase gasosa e em solução aquosa apresentam similaridades impressionantes, as quais requerem uma explicação comum. O principal desenvolvimento do modelo de Lewis do par de elétrons livre foi promovido pelo uso destas idéias para explicar reações entre bases tais como amônia e sais metálicos para formar o que atualmente conhecemos como complexos. A criação de novos modelos de acidez está prevista pela exploração de explicações do fenômeno. Posteriormente investigaremos se esta abordagem é adotada em livros didáticos de química. Um histórico detalhado da produção destes modelos é apresentado de modo que uma comparação apropriada entre o ensino e os modelos históricos possa ser feita.

\section{Modelos de acidez}

Uma variedade de representações de ácidos foi criada no desenvolvimento da Química. Em ordem cronológica, são as seguintes: 


\section{1. Ácidos são substâncias com propriedades particulares, tais como:}

a) sabor azedo;

b) capacidade de mudança da cor de certos pigmentos (indicadores);

c) capacidade de reação com metais reativos, produzindo hidrogênio;

d) capacidade de reação com carbonatos, produzindo gás carbônico;

e) capacidade de reação com bases, perdendo suas propriedades ácidas através da neutralização.

Atualmente sabe-se que estar em solução aquosa é um aspecto importante para os ácidos exibirem suas propriedades.

É provável que as substâncias tenham sido primeiramente classificadas como ácidos com base no sabor (Brock 1992), e que no desenvolvimento da mineração tenha-se constatado que os ácidos produzem efervescência quando em contato com rochas calcárias. Adicionalmente a estas propriedades e de posse de outras observações, surgiu a idéia de que os ácidos seriam substâncias que poderiam mudar a cor de vários pigmentos extraídos de plantas, e isto eventualmente se tornou parte do método de identificação da natureza ácida de um composto. A reação com carbonatos, e posteriormente com outras bases, produziu a noção de que ácidos poderiam perder suas propriedades, ou se tornarem neutralizados.

Na explicação do que é um ácido, este é descrito simplesmente como uma substância que possui uma série de propriedades, ou que funciona de um determinado modo. Esta é uma classificação operacional, amplamente utilizada por químicos, tanto novatos e como experientes, ainda hoje.

\section{2. Ácidos são substâncias que contêm oxigênio (Lavoisier)}

Tentativas foram feitas para explicar as propriedades dos ácidos em termos mais fundamentais do que as meras descrições das propriedades gerais, tais como: a explicação de que substâncias ácidas têm sabor azedo porque contêm partículas com bordas finas que machucam a língua. Entretanto, a preocupação em se tentar compreender as queimaduras que os ácidos provocam deu origem à idéia de que os ácidos continham oxigênio. Neste momento, o trióxido de enxofre foi entendido como o "ácido sulfúrico" e o ácido sulfúrico, como nós conhecemos agora, era o "ácido" (trióxido de enxofre) na forma hidratada. O significado do solvente não estava claro nessa época. Um sal era simplesmente a combinação entre um óxido ácido (ou ácido, como Lavoisier descreveu) e um óxido básico (ou óxido de um metal). Isto estava de acordo com a visão dualística da 
química na época, que atribuía a muitas reações químicas a neutralização de propriedades opostas. Neste modelo de ácido, a atenção está nas espécies envolvidas, isto é, que um ácido deve conter oxigênio.

\section{3. Ácidos são substâncias que contêm hidrogênio (Priestley)}

Esta idéia foi proposta após uma investigação considerável do ácido clorídrico, denominado gás de ácido marinho (porque era produzido de sal comum) ou ácido muriático (devido ao fato de ser um ácido formado por um óxido não-metálico). De uma forma interessante, um dos primeiros desafios para o modelo do oxigênio surgiu quando Scheele, trabalhando em uma indústria de minas sueca, foi solicitado para investigar a pirolusita (ou dióxido de manganês) (Goodman e Russell, 1991). Scheele adicionou ácido clorídrico em um dos seus primeiros testes. A produção de cloro resultou na posterior identificação deste novo elemento, após uma tentativa infrutífera de se atribuir sua natureza como sendo a de um óxido de um outro elemento. Tal produção também deu origem à idéia de que existiam dois tipos de ácidos, um contendo oxigênio e outro contendo hidrogênio. Foi creditado a Priestley, após combinar estes dois tipos de ácidos com a ação da água em óxidos ácidos, a autoria de um modelo mais inclusivo, onde todos os ácidos devem conter hidrogênio. Novamente a atenção é na espécie envolvida, isto é, em um ácido deve haver hidrogênio.

\section{4. Ácidos são substâncias que produzem íons hidrogênio em solução (Arrhenius)}

Esta idéia surgiu de duas séries de investigações: a primeira realizada por Raoult nas medidas do abaixamento do ponto de congelamento do ácido etanóico glacial, e a segunda por Arrhenius nas medidas de condutividade de uma série de soluções. Parece que havia uma prática de se usar a eletricidade como um modo de induzir tranformações químicas, e isto estava relacionado a uma tendência crescente de tentativas objetivando reações quantitativas. A precisão relativa das medidas de Arrhenius e Raoult foi extraordinária para a época. Ambas as investigações apontaram para o modelo de dissociação parcial em íons, e o conceito de ácido fraco como oposto ao de ácido forte. Um ácido fraco foi definido como sendo dificilmente dissociado em íons, e um ácido forte foi descrito como aquele quase totalmente dissociado. Interessantemente, a evidência do ácido sulfúrico nesta etapa apontou para a dissociação em duas partículas, as quais nós conhecemos agora como sendo o íon hidrônio e o íon hidro- 
genosulfato. A segunda dissociação em sulfato dificilmente poderia ser verificada nas condições experimentais que eles trabalharam.

Investigações posteriores da natureza do íon hidrogênio em solução aquosa levou à representação deste como $\mathrm{H} 3 \mathrm{O}+$. O significado do solvente, universalmente a água neste modelo, é encravado na explicação de como o íon $\mathrm{H} 3 \mathrm{O}+$ é produzido, sendo que este pode ser considerado um próton ligado a uma molécula de água. Na extensão deste modelo de acidez, também proposto por Arrhenius, a base é vista como uma substância que produz o íon hidróxido em solução. A neutralização é vista como a reação entre o íon hidrônio e o íon hidróxido para produzir moléculas de água. Apesar da maior sofisticação deste modelo, a atenção é ainda nas espécies, isto é, nos íons hidrônio (hidrogênio) e íons hidróxido em ácidos e bases, respectivamente. O significado do solvente começa a ser notado mais fortemente neste estágio do desenvolvimento das idéias sobre acidez.

\section{5. Ácidos são doadores de prótons (Brönsted-Lowry).}

Este modelo integra idéias separadas de ácido e base promovendo os conceitos de ácido conjugado e base conjugada. Neste modelo, um ácido está apenas atuando quando pode doar um próton a uma base. Também é utilizada a noção de equilíbrio para considerar a reação reversa como uma reação ácido-base. Brönsted-Lowry criou seu modelo para explicar neutralizações, tais como reações entre cloreto de hidrogênio gasoso e amônia produzindo cloreto de amônio, de modo semelhante à reação em solução aquosa entre essas duas substâncias. Neste sentido, é uma tentativa em se compreender de maneira mais fundamental o comportamento dos ácidos, criando um modelo que seja independente do solvente. Este modelo também pode ser usado para se estender o valor das reações ácido-base para reações em outros solventes, e para casos onde nenhum solvente está envolvido. A atenção neste modelo ainda está nas espécies sendo transformadas, ao invés da natureza das ligações químicas.

\section{6. Ácidos são receptores de par de elétrons (Lewis).}

Lewis estava preocupado com o par de elétrons livre e as discussões em seu grupo de pesquisa geralmente enfocavam o uso deste aspecto nas transformações químicas (Brock, 1992). Neste modelo, a atenção se desloca para a base ao invés do ácido. Ele tenta estender o pensamento sobre acidez concentrando-se nas ligações a serem formadas e quebradas. A principal mudança é representada pela atenção que agora não está mais 
sendo dada às espécies identificadas. Isto não é surpreendente para a época, na qual existia uma grande ênfase em se pensar sobre a formação e os diferentes tipos de ligação química, com tentativas de generalização das idéias sobre ligações. Este modelo pode dar uma dimensão diferente para as reações, as quais podem ser explicadas de maneira diversa, como por exemplo a formação de um íon complexo. A ampliação da concepção do que era considerada uma reação ácido-base pode ser o potencial, bem como a fraqueza, do novo modelo. Este pode ser generalizado a um nível onde se tratam todas as reações como sendo as mesmas, e aí está um ponto falho; algumas vezes é na diferenciação entre reações que se pode chegar à compreensão dos fatos.

\section{Usanovitch}

Entre Lewis e Usanovitch muitos trabalhos foram realizados em solventes diferentes da água, tais como amônia, dióxido de enxofre e ácido etanóico líquidos. Nestes solventes assume-se as seguintes reações de auto-ionização:

$$
\begin{aligned}
& 2 \mathrm{NH} 3=\mathrm{NH} 4++\mathrm{NH} 2- \\
& 2 \mathrm{SO} 2=\mathrm{SO} 2++\mathrm{SO} 2- \\
& 2 \mathrm{CH} 3 \mathrm{COOH}=\mathrm{CH} 3 \mathrm{COOH} 2++\mathrm{CH} 3 \mathrm{COO}-
\end{aligned}
$$

Titulações entre compostos de amônio e amidas, tionilos e sulfatos, ácidos fortes tais como ácido sulfúrico, e compostos etanoatos têm sido exploradas utilizando indicadores, termometria e métodos condutimétricos. Estas titulações demonstraram reações paralelas de neutralização em solução aquosa. Usanovitch, dedicando sua atenção a reações entre íons, estimou que nestas reações o ânion é simplesmente um transportador do par de elétrons livre. Esta explicação leva a um modelo de solvente, considerando um ácido como a substância que aumenta a concentração das espécies catiônicas na auto-ionização do solvente. Isto significa estender as idéias de ácidos para sistemas não-aquosos enquanto ainda explica as reações em água.

É possível dizer que algumas destas explicações são mais gerais que outras, que elas requerem uma compreensão mais profunda das anteriores. Entretanto, o que não está claro é se um professor experiente irá escolher naturalmente uma explicação mais fundamental do que um professor que está iniciando sua carreira. Parece ser o caso onde o professor iniciante se utiliza de uma ou duas explicações as quais estão mais disponíveis para 
ele. O professor mais experiente, com acesso a uma gama maior de modelos, parece escolher uma explicação para pôr em prática de acordo com a questão e com a pessoa que a formula. Deste modo, o professor experiente demonstra não apenas uma maior compreensão mas também uma maior facilidade em adequar a explicação a este propósito.

Um diagrama resumido destes modelos é mostrado na Tabela 1.

Tabela 1 - Modelos de ácidos e bases

\begin{tabular}{|c|c|c|c|c|c|}
\hline Modelos & Origem & $\begin{array}{c}\text { Dependência do } \\
\text { solvente }\end{array}$ & $\begin{array}{c}\text { Atributos } \\
\text { operacionais }\end{array}$ & $\begin{array}{l}\text { Espécies } \\
\text { definidas }\end{array}$ & $\begin{array}{c}\text { Ligações químicas } \\
\text { definidas }\end{array}$ \\
\hline Operacional & Desconhecida & Sim (água) & Sim & Não & Não \\
\hline Oxigênio & Lavoisier & Sim (água) & Sim & Sim & Não \\
\hline Hidrogênio & Priestley & Sim (água) & Sim & Sim & Não \\
\hline Íons Hidrogênio & Arrhenius & Sim (água) & Desconhecidos & Sim & Não \\
\hline $\begin{array}{c}\text { Doadores de } \\
\text { Prótons }\end{array}$ & Brönsted-Lowry & Não & Não & Sim & Não \\
\hline $\begin{array}{l}\text { Receptor de par } \\
\text { elétrons livre }\end{array}$ & Lewis & Não & Não & Não & $\mathrm{Sim}$ \\
\hline $\begin{array}{c}\text { Cátion } \\
\text { Solvatado }\end{array}$ & Usanovitch & Sim (qualquer) & Não & Sim & Näo \\
\hline
\end{tabular}

\section{Modelos de acidez como ferramentas exploratórias}

Cada modelo focaliza algum aspecto da acidez, explicando um número limitado de características da acidez. Uma hierarquia destas abordagens foi apresentada por Gilbert e Boutler (1998), resumidas como:

- descritiva

- interpretativa

- causal

- previsível

Esta organização de explicações tem sido utilizada como características de uma série de modelos de acidez nesta pesquisa, e é dada na Tabela 2 a seguir. 
Tabela 2 - Explicações para os modelos de ácidos e bases.

\begin{tabular}{|c|c|c|c|c|}
\hline Modelos & Origem & $\begin{array}{l}\text { Espécies } \\
\text { definidas }\end{array}$ & $\begin{array}{l}\text { Ligações } \\
\text { químicas } \\
\text { definidas }\end{array}$ & Tipo de explicação \\
\hline Operacional & Desconhecida & Não & Não & Descritiva \\
\hline Oxigênio & Lavoisier & Sim & Não & Interpretativa \\
\hline Hidrogênio & Priestley & Sim & Não & Interpretativa e causal \\
\hline Íons Hidrogênio & Arrhenius & Sim & Não & $\begin{array}{c}\text { Interpretativa, causal e } \\
\text { previsível }\end{array}$ \\
\hline Doadores de Prótons & Brönsted-Lowry & Sim & Não & $\begin{array}{c}\text { Interpretativa, causal e } \\
\text { previsivel }\end{array}$ \\
\hline $\begin{array}{l}\text { Receptor de par de } \\
\text { elétrons livre }\end{array}$ & Lewis & Não & Sim & $\begin{array}{c}\text { Interpretativa, causal e } \\
\text { previsível }\end{array}$ \\
\hline $\begin{array}{c}\text { Cátion } \\
\text { Solvatado }\end{array}$ & Usanovitch & Sim & Não & $\begin{array}{c}\text { Interpretativa, causal e } \\
\text { previsível } \\
\end{array}$ \\
\hline
\end{tabular}

\section{A pesquisa}

Estudantes que se encontram nos cursos "A Levels" tiveram que cobrir toda a classificação operacional dos ácidos, e muitos deles foram introduzidos ao modelo de Arrhenius de um ácido produzindo íons hidrogênio. O modelo de Lavoisier não é ensinado nas escolas da Inglaterra e do País de Gales, embora alunos em escolas de ensino fundamental (alunos em torno de 11 a 13 anos de idade) sejam usualmente introduzidos aos ácidos como solução aquosa de óxidos de não-metais, e base como óxidos metálicos.

Dois livros bastante utilizados nos cursos "A Levels" para o ensino de química foram analisados:

- Chemistry in Context ( $3^{\mathrm{a}}$ edição), de Graham Hill e John Holman, publicado por Thomas Nelson, (1989);

- A-Level Chemistry de E. N. Ramsden, publicado pela Editora Stanely Thornes Ltda., 1985,

e um novo livro direcionado ao mesmo público:

- Advanced Chemistry, de James Maple, publicado pela Editora John Murray Ltda., (1996).

Chemistry in Context foi escrito por dois examinadores bastante experientes do curso de química "A Levels" Nuffield 2, um dos mais populares cursos de química na Inglaterra e no País de Gales. O curso é altamente integrado em termos da físico-química com outras áreas 3 e é baseado em uma série de livros, os quais formam a base para o programa de estudos. "A-Level Chemistry" é direcionado mais especificamente aos 
programas tradicionais de química, enfatizando a aquisição de um conhecimento de fatos mais do que o curso Nuffield. Advanced Chemistry dá uma abordagem bastante animada, usando uma variedade de analogias e explicações de temas recentes.

Explicações de ácidos são usadas nas três áreas de cada um dos livros analisados. Em um capítulo, ou parte dele, os modelos e cálculos envolvendo ácidos formam o componente principal dos livros. Estes modelos são freqüentemente empregados nas seções tanto de química inorgânica como de química orgânica, usualmente de forma não explícita. Cada uma destas seções será considerada separadamente, identificando padrões comuns e ressaltando as diferenças.

\section{Explicações físico-químicas}

Todos os três livros dão uma cobertura de alguns dos modelos de acidez. Chemistry in Context inclui os modelos de Arrhenius e BrönstedLowry. A-Level Chemistry descreve os modelos de Arrhenius, BrönstedLowry e Lewis, bem como dá uma introdução à classificação operacional. Advanced Chemistry inclui o modelo de oxigênio de Lavoisier e cita Brönsted-Lowry, mas descreve brevemente o modelo de Arrhenius. Os três livros incluem seções extensivas de cálculos de: $\mathrm{pH}$ para ácidos fortes e fracos, do produto iônico da água e escalas de $\mathrm{pH}$, das mudanças de $\mathrm{pH}$ durante as titulações, dos cálculos de pH em soluções-tampão e sobre o conceito de indicadores de forma semi-quantitativa. Em todos os cálculos de $\mathrm{pH}$, há muito pouca justificativa de seu uso pelos autores, e é amplamente assumido que é uma parte essencial do estudo da química neste estágio. Nenhum dos livros discute porque um ácido é fraco, a não ser para produzir definições taulotógicas de que um ácido é fraco porque é dificilmente dissociado em íons, ou porque apresenta um determinado valor de $\mathrm{pH}$, ou porque seus ânions atraem prótons.

Chemistry in Context dá um exemplo de cálculos de $\mathrm{pH}$ para ácido sulfúrico baseado na noção de dissociação completa em íons sulfato e íons hidrônios, sendo que a situação mais adequada seria a de que o ânion hidrogenosulfato comporta-se como um ácido fraco. Nas seções de cálculos, os modelos de acidez não são referenciados e existe uma inconsistência no uso de íons hidrogênio e hidrônio nas equações. 
Na seção de físico-química do livro A-Level Chemistry, uma proposta para se explicar as forças relativas de vários ácidos etanóicos clorados é baseada nas forças de grupos que têm a capacidade de retirar elétrons. Um espaço é dado para a titulação de carbonatos como sendo um processo que envolve duas etapas, e seu uso na titulação da mistura de carbonato e hidrogenocarbonato. Atualmente isto é considerado um tanto quanto tradicional no Reino Unido e não está aparecendo como necessário nos últimos programas de cursos. Há uma discussão sobre o sistema da amônia líquida quando se discute o modelo de Brönsted-Lowry de transferência de prótons.

Advanced Chemistry apresenta uma discussão da evolução e do significado do modelo de Lavoisier, levando a Arrhenius e a BrönstedLowry. O livro discute um ácido como uma substância que reage com uma base para dar um sal e água somente, o que exclui os carbonatos como bases. Isto é uma contradição, como o modelo operacional proposto por Brock (1992), que simplesmente diz que uma base neutraliza um ácido, incluindo os carbonatos como bases.

\section{Química Inorgânica}

Chemistry in Context focaliza, na maioria das discussões sobre ácido-base em química inorgânica, a produção de íons hidrônio e hidróxido, e descreve ácidos como materiais os quais reagem com íons hidróxidos, utilizando-se de equações iônicas, principalmente, para explicar tais propriedades. Muito pouca atenção é dada aos aspectos operacionais dos ácidos nas explicações (exemplos: efeito nas reações com metais, em papel indicador, com carbonatos). Na discussão da acidez de haletos de hidrogênio simplesmente se estabelece que estes sejam ácidos. Uma explicação da acidez em termos da natureza iônica ou covalente das ligações em óxidos é dada para alumínio, grupo (IV) e óxidos de metais de transição. Nessa seção não há referência à qualquer base para cálculos ou para comparação através das constantes de dissociação dos ácidos.

A química dada no cursos "A-Level" simplesmente estabelece que os hidróxidos de metais alcalinos são alcalinos, sem nenhuma explicação, nem mesmo em termos da produção de íons hidróxido. Considera-se que o íon alumínio tenha caráter ácido devido à produção de íons hidrônio, mas 
o modelo relevante de Arrhenius não é mencionado explicitamente. Reações com álcalis são apresentadas em reações com íons hidróxidos, com algumas equações representadas na forma iônica e outras na forma molecular. Parece não haver consistência na forma de representação. As forças de ácidos em haletos de hidrogênio são pensadas em termos das constantes de dissociação, mas não há nenhum detalhe das espécies formadas, isto é, é um hidrogênio ou um íon hidrônio? Amônia é discutida como uma base devido ao fato de reagir com ácidos, mas existe uma visão implícita dada em um diagrama onde um par de elétrons livre está envolvido, isto é, o modelo de Lewis está sendo utilizado. Dióxido de carbono como um óxido ácido é explicado pela produção do ácido carbônico molecular, referindo-se à idéia de que um ácido contém hidrogênio, de acordo com o modelo de Priestley, embora não definido claramente.

Advanced Chemistry usa a expressão "próton grudado" para explicar a reação do óxido de alumínio, ou seja, fundamentalmente é o modelo de Arrhenius sendo utilizado. Amônia líquida é discutida, íons amida são identificados como bases, mas não há descrição de qual modelo de ácidos está sendo exposto no livro. De forma interessante, uma menção sobre as similaridades do comportamento de nucleófilos e base é feita, sendo justificada na utilização de pares de elétrons nos dois casos, embora Lewis não seja referenciado. A acidez do dióxido de carbono é discutida em termos da formação de íons hidrogênio, de volta ao modelo original de Arrhenius, embora seu nome não seja mencionado.

\section{Química Orgânica}

Nos capítulos de Química Orgânica, fazendo parte de diversos mecanismos, reações de transferências de prótons são apresentadas. Usualmente são descritas na forma iônica, porém são mostradas como fatos e não são consideradas reações ácido-base. Todos os três livros apresentam, de acordo com o modelo operacional, uma discussão sobre a acidez dos ácidos carboxílicos e de uma variedade de compostos contendo hidroxilas, tais como: álcoois em reações com sódio metálico (embora as seções de físico-química não mencionem este metal como um exemplo) e hidróxido de sódio e carbonato de sódio para formar sais. O termo $\mathrm{pH}$ raramente é mencionado. As constantes de dissociação de ácidos são utilizadas para 
demonstrar que eles são ácidos fracos. Aminas são discutidas como sendo bases em função de suas constantes de basicidade e pares de elétrons livres, embora, novamente, o modelo de Arrhenius não seja mencionado. O modelo de Brönsted-Lowry é citado nas reações de aminas. Todos os três livros simplesmente estabelecem que os amino-ácidos existem como um "zwitterion", sem nenhuma referência a uma transferência interna de próton de Brönsted-Lowry. A oportunidade para descrever um aminoácido como seu próprio conjugado, embora em uma forma isomérica (!) é perdida.

Existe uma tentativa no livro A-Level Chemistry de explicar a acidez do etanol em termos da polaridade da ligação oxigênio-hidrogênio. Comportamento ácidos diferentes são simplesmente "explicados" em termos da capacidade dos substituintes em retirar elétrons.

\section{Discussão}

Diversos modelos provêm explicações de fenômenos (Gilbert e Boulter, 1998), e a inclusão destes nos programas de química pode ser julgada pelo uso pelos quais estão submetidos. Em seções de físico-química, onde os modelos são introduzidos, a razão para a inclusão de um ou outro modelo não foi apresentada nos livros revisados. As progressões são freqüentemente apresentadas em função do desenvolvimento histórico, como também do poder de explicação para um determinado fenômeno químico. É possível que em alguns artigos de revisão, os potenciais e limitações de cada modelo sejam dados após a descrição de cada modelo, mas este não é o caso dos livros aqui analisados. Nas seções de aplicações da química, isto é, na química inorgânica e orgânica, não há nenhuma referência direta do modelo de ácido em qualquer momento, e os modelos são simplesmente utilizados como se fossem fatos. Ao invés disto, parece que o uso de modelos é eclético, e os leitores são desafiados a descobrir em qual dos modelos está sendo utilizado, porque é considerado o mais apropriado, e porque outro modelo não foi escolhido. Frente a esta situação de se tentar compreender os modelos que estão sendo utilizados, não é surpreendente que alguns dos alunos adotem estratégias para a aprendizagem de cada modelo e as usem de maneira decorada, colocando grande esforço na capacidade mental de memorização do indivíduo. Tal 
como uma estratégia, a aplicação com sucesso dos modelos de acidez em novas situações é comprometida.

Há uma considerável variação no tratamento de modelos ou explicações de acidez nos três livros. Chemistry in Context é particularmente pobre neste aspecto e A-Level Chemistry falha em não dar nenhuma discussão coerente da utilidade relativa desses modelos. Mesmo o livro Advanced Chemistry, que dá uma descrição mais completa, falha em explorar a oportunidade de discutir a natureza dinâmica da ciência, sempre em busca de modelos mais inclusivos, gerais e que ainda permaneçam úteis.

A ênfase no resto dos capítulos de físico-química é no vasto número de exercícios de cálculos de $\mathrm{pH}$, de um modo ou outro. Parece haver muito pouco esforço em explicar o porquê de um ácido ser fraco, e simplesmente verifica-se o desenvolvimento de habilidades aritméticas dos dados fornecidos. Não há discussão do papel desses cálculos na compreensão dos modelos de ácidos nos capítulos.

Pode-se imaginar que a aplicação desses modelos deva vir nos capítulos de química inorgânica e orgânica. Entretanto, observa-se que há uma inconsistência no uso desses modelos, e que existe uma discussão bastante difícil dos valores dos modelos na compreensão das reações químicas destes compostos.

O modelo de Brönsted-Lowry raramente é referido como sendo o mesmo apresentado nas seções de físico-química. O modelo de Arrhenius é o mais utilizado, mas seu potencial em explicar uma grande parte de fenômenos químicos é ignorado. O modelo de Lewis falha em ser significativo para qualquer explicação de química inorgânica e orgânica. As constantes de dissociação de ácidos são usadas para indicar as forças relativas (freqüentemente na forma de $\mathrm{pKa}$ e parece ser um desafio diferente para a compreensão do aluno), mas as habilidades em realizar cálculos nos capítulos de físico-química não são utilizadas na aplicação nos capítulos de química inorgânica e orgânica. Independentemente de ser uma parte estipulada do programa dos cursos, e por conseguinte necessária nos livros didáticos, é difícil justificar a quantidade excessiva de cálculos a serem ensinados, exceto talvez em termos de material para futuros exames, os quais pedem respostas a serem assinaladas como corretas ou incorretas.

Há razões legítimas para a escolha de determinados modelos para diferentes aspectos da química, sendo que cada modelo focaliza um aspecto específico da acidez. Em química inorgânica, reações de metais alcalinos com outras espécies podem bem ser entendidas como simplesmente reações com íons hidróxidos. O caráter básico de um íon óxido em soluções aquosas de óxidos alcalinos pode ser explicado pela 
formação de íons hidróxidos nas reações com água (explicação descritiva e explicativa baseada no modelo de Arrhenius), ou na natureza básica do íon hidróxido em atrair um próton da molécula de água (explicação interpretativa ou causal baseada no modelo de Brönsted-Lowry), ou na capacidade de pares de elétrons livres em um íon óxido se ligar a um próton (explicação interpretativa e causal baseada no modelo de Lewis). Um série similar de argumentos aplica-se à discussão da basicidade da metilamina (produz íons hidróxido em solução, atrai prótons das moléculas de água, tem par de elétrons livre que se liga a um próton). O professor de química é aquele que necessita ter um repertório de modelos e pode escolher o mais apropriado para cada circunstância.

\section{Implicações para uma reforma de programa e métodos de ensino}

A evidência dada no início deste artigo indica que os alunos encontram dificuldades em entender e aplicar os modelos de ácidos. Os livros analisados dão uma indicação de algumas das razões que possam explicar este fenômeno. Modelos são apresentados sem referência ao desenvolvimento da natureza das ciências, isto é, a criação de explicações e modelos para promover a compreensão dos dados experimentais, para generalizar novas situações. Eles não são então utilizados em Química de modo consistente e coerente. Alguns dos modelos nem são utilizados por alguns dos autores. Os cálculos tomam grande parte do curso sem uma compreensão do significado matemático dos resultados. Em nenhum ponto dos livros analisados é dito que os cálculos baseados nos modelos de equilíbrio ácido-base são suportados por evidências experimentais. Deveríamos nos questionar sobre se gostaríamos de ver a química como um componente abstrato em seções de físico-química ou como evidências experimentais em seções de química inorgânica e orgânica, insuficientemente relatadas como idéias teóricas.

Alguns exemplos de química inorgânica são dados nas tabelas 3 a 6 e mostram como estes podem ser tratados explicitamente enquanto processos para a criação de modelos. 
Tabela 3 - Exemplos de acidez para química inorgânica.

\begin{tabular}{|c|c|c|c|c|c|}
\hline Ácidos & $\begin{array}{l}\text { Modelo operacional } \\
\text { em solução aquosa- }\end{array}$ & $\begin{array}{l}\text { Modelo de } \\
\text { Arrhenius, } \\
\left(\mathrm{H}^{+} / \mathrm{H}_{3} \mathrm{O}^{+}\right) \\
\text {em solução } \\
\text { aquosa- }\end{array}$ & $\begin{array}{c}\text { Modelo de } \\
\text { Brönsted-I nwry, } \\
\text { transferência de } \\
\mathbf{H}^{+} \text {- }\end{array}$ & $\begin{array}{c}\text { Modelo de Lewis, } \\
\text { par de clétrons } \\
\text { livre }\end{array}$ & $\begin{array}{l}\text { Avaliação e } \\
\text { comentário }\end{array}$ \\
\hline $\begin{array}{l}\text { Acido clorídrico } \\
\text { HCl } \\
\text { (comso um exemplo } \\
\text { de ácido mineral } \\
\text { forte) }\end{array}$ & $\begin{array}{c}\mathrm{pH}<7 \\
+\mathrm{Mg} \rightarrow \text { hidrogênio } \\
+\mathrm{Na}_{2} \mathrm{CO}_{1} \rightarrow \mathrm{CO}_{2} \\
+\mathrm{CuO} \rightarrow \mathrm{CuCl}_{2} \\
+\mathrm{NaOH} \rightarrow \mathrm{NaCl} \\
\text { odor } / \text { sabor } \\
\end{array}$ & $\begin{array}{c}\mathrm{HCl}+\mathrm{aq} \rightarrow \mathrm{H}^{\top}+\mathrm{Cl}^{-} \\
\mathrm{K}_{4} \text { grande }\end{array}$ & $\begin{array}{c}\mathrm{HCl}+\mathrm{H}_{2} \mathrm{O} \rightarrow \\
\mathrm{H}_{3} \mathrm{O}^{+}+\mathrm{Cl}^{-}\end{array}$ & Não é aplicável & $\begin{array}{l}\text { Todos os modelos } \\
\text { são úteis, exceto o } \\
\text { de Lewis. }\end{array}$ \\
\hline $\begin{array}{c}\text { Ácido clórico(I) } \\
\text { HOCl } \\
\text { (como um exemplo } \\
\text { de ácido inorgânico } \\
\text { fraco) } \\
\end{array}$ & 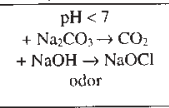 & $\begin{array}{l}\mathrm{HOCl}+\mathrm{aq} \rightarrow \\
\mathrm{H}_{3} \mathrm{O}^{+}+\mathrm{Cl}^{-} \\
\mathrm{K}_{\mathrm{a}} \text { pequeno }\end{array}$ & $\begin{array}{c}\mathrm{HOCl}+\mathrm{H}_{2} \mathrm{O} \rightarrow \\
\mathrm{H}_{3} \mathrm{O}^{+}+\mathrm{OCl}^{-}\end{array}$ & Não é aplicável & $\begin{array}{l}\text { Todus os modelos } \\
\text { säo uteis. exceto o } \\
\text { de Lewis. }\end{array}$ \\
\hline $\begin{array}{l}\text { Cloreto de alumínio } \\
\text { (näo contém } \\
\text { hidrogênio) }\end{array}$ & $\begin{array}{c}\mathrm{pH}<7 \\
+\mathrm{Na}_{2} \mathrm{CO}_{3} \rightarrow \mathrm{CO}_{2} \\
+\mathrm{Mg} \rightarrow \mathrm{H}_{2} \\
\text { odor }\end{array}$ & $\begin{array}{c}\mathrm{Al}\left(\mathrm{H}_{2} \mathrm{O}\right)_{6}{ }^{3+}= \\
\mathrm{Al}\left(\mathrm{H}_{2} \mathrm{O}\right)_{5} \mathrm{OH}^{2+}+\mathrm{H}^{+} \\
\mathrm{K}_{: \text {: muito grande }}\end{array}$ & $\begin{array}{c}\mathrm{Al}\left(\mathrm{H}_{2} \mathrm{O}\right)_{6}{ }^{3+}+\mathrm{H}_{2} \mathrm{O}= \\
\mathrm{Al}\left(\mathrm{H}_{2} \mathrm{O}\right)_{5} \mathrm{OH}^{2+}+ \\
\mathrm{H}_{3} \mathrm{O}^{+}\end{array}$ & $\begin{array}{c}\mathrm{AlCl}_{3}+\mathrm{NH}_{3} \rightarrow \\
\mathrm{H}_{3} \mathrm{~N}-\mathrm{AlCl}_{3}\end{array}$ & $\begin{array}{l}\text { Todos os modelos } \\
\text { sāo úteis. Arhenius } \\
\text { necessita envolver } \\
\text { a formação do ion } \\
\text { aluminio hidyatado e } \\
\text { da hidrolise. }\end{array}$ \\
\hline $\begin{array}{l}\text { Trióxido de enxofre } \\
\text { (como um exemplo } \\
\text { de óxido) }\end{array}$ & $\begin{array}{c}\mathrm{pH}<7 \\
+\mathrm{Va}_{2} \mathrm{CO}_{3} \rightarrow \mathrm{CO}_{2} \\
+\mathrm{Mg}_{2} \rightarrow \mathrm{H}_{2} \\
+\mathrm{CuO} \rightarrow \mathrm{CuSO}_{4} \\
+\mathrm{NaOH} \rightarrow \mathrm{Na}_{2} \mathrm{SO}_{4} \\
\text { odor }\end{array}$ & $\begin{array}{c}\mathrm{SO}_{3}+\mathrm{H}_{2} \mathrm{O} \rightarrow \mathrm{H}_{2} \mathrm{SO}_{4} \\
\mathrm{H}_{2} \mathrm{SO}_{4}+\mathrm{aq} \rightarrow \\
\mathrm{H}^{-}+\mathrm{HSO}_{4} \\
\text { Aplicável para } \\
\mathrm{H}_{2} \mathrm{SO}_{4} \\
\mathrm{~K}_{2} \text { para a promeina } \\
\text { dissocią̧ăo muito } \\
\text { grande }\end{array}$ & $\begin{array}{c}\text { Apenas aplicivel } \\
\text { fara } \mathrm{H}_{2} \mathrm{SO}_{4} \\
\mathrm{H}^{+}+\mathrm{NH}_{4} \rightarrow \mathrm{NH}_{4}^{+}\end{array}$ & $\mathrm{SO}_{3}+\mathrm{O}^{2} \rightarrow \mathrm{SO}_{4}^{2}$ & $\begin{array}{l}\text { Todos us modelos são } \\
\text { úteis, mas os modelos } \\
\text { de Autenius } \\
\text { Brönsted-Lowry ne- } \\
\text { cessitam envolver a } \\
\text { formas do de um in- } \\
\text { temnediátio de } \mathrm{H}_{2} \mathrm{SO}_{4} \\
\text { nat reatcāo de } \mathrm{SO}_{3} \text { com } \\
\text { agua. }\end{array}$ \\
\hline
\end{tabular}

Tabela 4 - Exemplos de basicidade para química inorgânica.

\begin{tabular}{|c|c|c|c|c|c|}
\hline Bases & $\begin{array}{l}\text { Modclo operacional } \\
\text { em solução aquosa- }\end{array}$ & $\begin{array}{c}\text { Modelo de } \\
\text { Arrhenius, } \\
\left(\mathbf{H}^{+} / \mathbf{H}_{3} \mathbf{O}^{+}\right) \\
\text {em solução } \\
\text { aquosa- }\end{array}$ & $\begin{array}{c}\text { Modelo de } \\
\text { Brönsted-Lowry, } \\
\text { transferência de } \\
\mathbf{H}^{+}-\end{array}$ & $\begin{array}{l}\text { Modelo de Lewis, } \\
\text { par de clétrons } \\
\text { livre }\end{array}$ & $\begin{array}{l}\text { Avaliaçāo e } \\
\text { comentário }\end{array}$ \\
\hline Hidróxido de sódio & $\begin{array}{c}\mathrm{pH}>7 \\
+\mathrm{HCl} \rightarrow \mathrm{NaCl}\end{array}$ & $\begin{array}{l}\text { Produz OH em } \\
\text { soluçāo aquosa }\end{array}$ & $\begin{array}{c}\mathrm{OH}^{-}+\mathrm{H}_{3} \mathrm{O}^{+} \rightarrow \\
2 \mathrm{H}_{2} \mathrm{O}\end{array}$ & $\begin{array}{l}\mathrm{Zn}^{2+}+4 \mathrm{OH}^{-} \rightarrow \\
\mathrm{Zn}(\mathrm{OH})_{4}^{2-}\end{array}$ & $\begin{array}{l}\text { Todos os modelos } \\
\text { são útcis. Näo neces- } \\
\text { sitam de interme- } \\
\text { diários. }\end{array}$ \\
\hline Oxido de magnćsio & $\begin{array}{c}\mathrm{pH}>7 \\
+\mathrm{HCl} \rightarrow \mathrm{MgCl}_{2}\end{array}$ & $\begin{array}{l}\text { Produz OH cm } \\
\text { solução aquosa } \\
\mathrm{K}_{\mathrm{h}} \text { grande }\end{array}$ & $\begin{array}{c}\mathrm{O}^{2 \cdot}+\mathrm{H}_{2} \mathrm{O} \rightarrow 2 \mathrm{OH}^{-} \\
\mathrm{O}^{2+}+2 \mathrm{H}_{3} \mathrm{O}^{+} \rightarrow \\
3 \mathrm{H}_{2} \mathrm{O}\end{array}$ & $\mathrm{O}^{2-}+\mathrm{SO}_{3} \rightarrow \mathrm{SO}_{4}^{2-}$ & $\begin{array}{l}\text { Todos os modelos } \\
\text { são úteis. A hidra } \\
\text { tação é necessária } \\
\text { para a explicação. }\end{array}$ \\
\hline Amônia & $\begin{array}{c}\mathrm{pH}>7 \\
+\mathrm{HCl} \rightarrow \mathrm{NH}_{4} \mathrm{Cl}\end{array}$ & $\begin{array}{c}\mathrm{NH}_{3}+\mathrm{H}_{2} \mathrm{O}= \\
\mathrm{NH}_{4}^{+}+\mathrm{OH}^{-} \\
\mathrm{K}_{6} \text { pequeno }\end{array}$ & $\begin{array}{c}\mathrm{NH}_{3}+\mathrm{HNO}_{3} \rightarrow \\
\mathrm{NH}_{4}{ }^{=}+\mathrm{NO}_{3}\end{array}$ & $\begin{array}{c}\mathrm{NH}_{3}+\mathrm{BF}_{3} \rightarrow \\
\mathrm{F}_{3} \mathrm{BNH}_{3}\end{array}$ & $\begin{array}{l}\text { Etapas intermedí- } \\
\text { rias são necessánia } \\
\text { para o nodelo de } \\
\text { Aurherius. }\end{array}$ \\
\hline Carbonato de sódio & $\begin{array}{c}\mathrm{pH}>7 \\
+\mathrm{HCl} \rightarrow \mathrm{NaCl}\end{array}$ & $\begin{array}{c}\mathrm{CO}_{3}{ }^{2}+\mathrm{H}_{2} \mathrm{O} \rightarrow \\
\mathrm{HCO}_{3}+\mathrm{OH} \\
\mathrm{K}_{6} \text { muito pequeno }\end{array}$ & $\begin{array}{c}\mathrm{CO}_{3}{ }^{2}+\mathrm{CH}_{3} \mathrm{COOH} \\
\rightarrow \mathrm{HCO}_{3}+ \\
\mathrm{CH}_{3} \mathrm{COO}^{\circ}\end{array}$ & $\begin{array}{c}\mathrm{CO}_{3}{ }^{2-}+\mathrm{HNO}_{3} \rightarrow \\
2 \mathrm{NO}_{3}+\mathrm{H}_{2} \mathrm{CO}_{3} \\
\mathrm{H}_{2} \mathrm{CO}_{3} \rightarrow \\
\mathrm{CO}_{1}+\mathrm{H}_{2} \mathrm{O}\end{array}$ & $\begin{array}{l}\text { Todos os modelos } \\
\text { sāo úteis em todos } \\
\text { os aspectos. }\end{array}$ \\
\hline
\end{tabular}


Tabela 5 - Exemplos de acidez para química orgânica.

\begin{tabular}{|c|c|c|c|c|c|}
\hline Ácidos & $\begin{array}{l}\text { Modelo operacional } \\
\text { em solução aquosa- }\end{array}$ & $\begin{array}{l}\text { Modelo de } \\
\text { Arrhenius, } \\
\left(\mathrm{H}^{+} / \mathrm{H}_{3} \mathrm{O}^{+}\right) \\
\text {em soluçäo } \\
\text { aquosa- }\end{array}$ & $\begin{array}{c}\text { Modelo de } \\
\text { Brönsted-Lowry, } \\
\text { transferência de } \\
\mathbf{H}^{+} \text {. }\end{array}$ & $\begin{array}{c}\text { Modela de Lewis, } \\
\text { par de clćtrons } \\
\text { livre }\end{array}$ & $\begin{array}{l}\text { Avaliação e } \\
\text { comentário }\end{array}$ \\
\hline $\begin{array}{c}\text { Ácido etanóico } \\
\mathrm{H}, \mathrm{CCOOH}\end{array}$ & $\begin{array}{c}\mathrm{pH}<7 \\
+\mathrm{Mg} \rightarrow \text { hidrogênio } \\
+\mathrm{Na} \mathrm{CO}_{3} \rightarrow \mathrm{CO}_{2} \\
+\mathrm{CuO} \rightarrow \text { sal de cobre } \\
+\mathrm{NaOH} \rightarrow \text { sal } \\
\text { odor isabor }\end{array}$ & $\begin{array}{c}\mathrm{H}_{3} \mathrm{CCOOH}+\mathrm{aq} \\
\mathrm{H}^{+}+\mathrm{H}_{3} \mathrm{CCOO} \\
\mathrm{K}_{4 i} \text { pequeno }\end{array}$ & $\begin{array}{c}\mathrm{H}_{3} \mathrm{CCOOH}+\mathrm{H}_{2} \mathrm{O} \rightarrow \\
\left.\mathrm{H}_{3} \mathrm{O}^{+}+\mathrm{H}_{3} \mathrm{CCO}\right)^{-}\end{array}$ & Nāo ć aplicável. & $\begin{array}{l}\text { Todos os modelos } \\
\text { sāo útcis, exceto o } \\
\text { de Lewis. }\end{array}$ \\
\hline $\begin{array}{c}\text { Etanol } \\
\mathrm{C}_{2} \mathrm{H}_{5} \mathrm{OH}\end{array}$ & $+\mathrm{Na} \rightarrow$ hidrogênio & $\begin{array}{c}\mathrm{C}_{2} \mathrm{H}_{5} \mathrm{OH}+\mathrm{aq} \rightarrow \\
\mathrm{H}^{+}+\mathrm{C}_{2} \mathrm{H}_{5} \mathrm{O}^{-} \\
\mathrm{K}_{2} \text { muito pequeno }\end{array}$ & $\begin{array}{c}\mathrm{C}_{2} \mathrm{I}_{5} \mathrm{OH}+\mathrm{H}_{2} \mathrm{O} \rightarrow \\
\mathrm{H}_{3} \mathrm{O}^{+}+\mathrm{C}_{2} \mathrm{H}_{5} \mathrm{O}^{\circ}\end{array}$ & $\begin{array}{l}\text { Nâo é aplicável } \\
\text { como um ácido. }\end{array}$ & $\begin{array}{c}\text { Todos os modelos } \\
\text { sāo úteis, cxccto o } \\
\text { de Lewis. }\end{array}$ \\
\hline $\begin{array}{c}\text { Fenol } \\
\mathrm{C}_{n} \mathrm{H}_{3} \mathrm{OH}\end{array}$ & $\begin{array}{l}+\mathrm{Na} \rightarrow \text { hidrogênio } \\
+\mathrm{NaOH} \rightarrow \text { sal }\end{array}$ & $\begin{array}{c}\mathrm{C}_{6} \mathrm{H}_{5} \mathrm{OH}+\mathrm{aq} \rightarrow \\
\mathrm{H}^{+}+\mathrm{C}_{6} \mathrm{H}_{5} \mathrm{O} \\
\mathrm{K}_{\mathrm{i}} \text { pequeno }\end{array}$ & $\begin{array}{c}\mathrm{C}_{6} \mathrm{H}_{5} \mathrm{OH}+\mathrm{H}_{2} \mathrm{O} \rightarrow \\
\mathrm{H}_{3} \mathrm{O}^{+}+\mathrm{C}_{6} \mathrm{H}_{5} \mathrm{O}^{-}\end{array}$ & $\begin{array}{l}\text { Nāo é aplicível } \\
\text { como um úcido. }\end{array}$ & $\begin{array}{l}\text { Todos os modelos } \\
\text { sāo úteis, exceto o } \\
\text { de Lewis. }\end{array}$ \\
\hline
\end{tabular}

Tabela 6 - Exemplos de basicidade para química orgânica.

\begin{tabular}{|c|c|c|c|c|c|}
\hline Bases & $\begin{array}{l}\text { Modelo operacional } \\
\text { em solução ayuesa- }\end{array}$ & $\begin{array}{c}\text { Modclo de } \\
\text { Arrhenius, } \\
\left(\mathrm{H}^{+} / \mathrm{H}_{3} \mathrm{O}^{+}\right) \\
\text {em soluçäo } \\
\text { aquosa- }\end{array}$ & $\begin{array}{c}\text { Modelo de } \\
\text { Brinsted-Lowry, } \\
\text { transferência de } \\
\mathbf{H}^{+} \text {. }\end{array}$ & $\begin{array}{c}\text { Modclo de Lewis, } \\
\text { par de elétrons } \\
\text { livre }\end{array}$ & $\begin{array}{l}\text { Avaliação e } \\
\text { comentário }\end{array}$ \\
\hline $\begin{array}{c}\text { Metilamitia } \\
\mathrm{CH}_{3} \mathrm{NH}_{2}\end{array}$ & $+\frac{\mathrm{pH}>7}{+\mathrm{HCl}} \stackrel{\mathrm{CH}_{3} \mathrm{NH}_{3} \mathrm{Cl}}{ }$ & $\begin{array}{c}\text { Produz OH em } \\
\text { soluçāo aquosa } \\
\mathrm{CH}_{3} \mathrm{NH}_{2}+\mathrm{H}_{2} \mathrm{O} \rightarrow \\
\mathrm{CH}_{3} \mathrm{NH}_{3}^{+}+\mathrm{OH}\end{array}$ & $\begin{array}{c}\mathrm{OH}^{-}+\mathrm{H}_{3} \mathrm{O}^{+} \rightarrow \\
2 \mathrm{H}_{2} \mathrm{O} \\
\mathrm{CH}_{3} \mathrm{NH}_{2}+\mathrm{H}_{3} \mathrm{O}^{+} \rightarrow \\
\mathrm{CH}_{3} \mathrm{NH}_{3}^{+}+\mathrm{H}_{2} \mathrm{O}\end{array}$ & $\begin{array}{l}\mathrm{Zn}^{2+}+4 \mathrm{CH}_{3} \mathrm{NH}_{2} \rightarrow \\
\mathrm{Zn}\left(\mathrm{CH}_{3} \mathrm{NH}_{2}\right)_{4}^{2-}\end{array}$ & $\begin{array}{l}\text { Todos as teorias são } \\
\text { úteis. Somente o } \\
\text { modelo de Arrhenius } \\
\text { necessita } \\
\text { intermediários. de }\end{array}$ \\
\hline $\begin{array}{l}\text { Propanona } \\
\mathrm{CH}_{3} \mathrm{COCH}_{4}\end{array}$ & $\begin{array}{c}\text { Nãu mostra } \\
\text { claramente reaçōes } \\
\text { hásicas } \mathrm{cm} \text { solução }\end{array}$ & $\begin{array}{c}\text { Produz } \mathrm{OH}^{-} \text {em } \\
\text { soluça aquosa a } \\
\text { partir do } \mathrm{H}_{3} \mathrm{O}^{+}\end{array}$ & $\begin{array}{c}\mathrm{CH}_{3} \mathrm{COCH}_{3}+\mathrm{H}_{3} \mathrm{O}^{+} \\
\rightarrow \mathrm{CH}_{3} \mathrm{COHCH}_{3}{ }^{+} \\
\text {Envolvido nas } \\
\text { reaçöes de catálise } \\
\text { ácidas. Ex. } \mathrm{I}_{2} \mathrm{com} \\
\text { propanona }\end{array}$ & $\begin{array}{c}\mathrm{CH}_{3} \mathrm{COCH}_{3}+\mathrm{H}_{3} \mathrm{O}^{+} \\
\rightarrow \mathrm{CH}_{3} \mathrm{COHCH}_{3}{ }^{+} \\
\text {O par de clétrons } \\
\text { livre do oxigênio } \\
\text { doa o próton }\end{array}$ & $\begin{array}{l}\text { Os modelos opera- } \\
\text { cional e de Arrhenius } \\
\text { nāo sāo úteis. }\end{array}$ \\
\hline
\end{tabular}

\section{Ações que poderiam ser desenvolvidas:}

1. incluir uma discussão da natureza das ciências, bem como esta se relaciona com o desenvolvimento dos modelos de acidez, tornando um exemplo claro e bem documentado deste processo;

2. aumentar a consistência nas explicações dos aspectos inorgânicos e orgânicos, por exemplo, usando apenas hidrogênio ou apenas íons hidrônio; 3. retirar muitos dos cálculos de $\mathrm{pH}$ agora requisitados ou relacioná-los mais claramente ao significado dos resultados.

4. incluir explicitamente em química inorgânica e orgânica, razões para a escolha de um modelo apropriado para demonstrar o processo de tomada de decisão da escolha de um modelo para um propósito diferente;

5. incluir um capítulo resumido que relacione todos os usos da acidez no livro, com uma discussão dos valores dos diferentes modelos. 


\section{Pesquisa futura}

\section{Questões da pesquisa que ainda precisam ser respondidas:}

1. Como um professor de química escolhe um modelo para aplicar em cada caso particular?

2. Usando o conceito de acidez, quais são as principais imposições para o desenvolvimento de um modelo na história?

3. Existe alguma lição a ser aprendida da resposta da segunda questão, que poderia nos ajudar a compreender como os alunos em sala de aula modificam seus pensamentos?

4. Os professores de química estabelecem que algum modelo é inferior a outro? Se isto ocorre, é possível que isto afete suas ações em sala de aula no momento em que se ensina um determinado modelo?

5. Existe algum modelo de ácido que seja difícil de se compreeender em um determinado estágio?

6. Quanto os professores experientes ou iniciantes se aproximam dos padrões adotados nos livros didáticos?

\section{RESUMO}

O presente artigo tem como objetivo explorar a apresentação de idéias sobre ácidos (e bases) em alguns livros didáticos utilizados no ensino de estudantes de 16 a 18 anos que tenham disciplinas de química nos cursos "A Levels" das escolas da Inglaterra e do País de Gales. Também pretende-se fazer uma comparação dos diferentes conceitos de ácidos com seus desenvolvimentos históricos, analisando a amplitude e a profundidade de poder exploratório de cada modelo. Além do interesse intrínseco, tem-se a impressão de que os professores aprendem muito em suas experiências sobre o que ensinar, e como desenvolver tais idéias, a partir dos livros didáticos utilizados. Isto se torna, provavelmente, mais comum do que o praticado anteriormente, onde reuniões administrativas nas escolas exigiam um 
tempo considerável de orientação de professores iniciantes por professores mais experientes.

\section{REFERÊNCIAS BIBLIOGRÁFICAS}

BROCK, W. H. The Fontana History of Chemistry Fontana Press, London, 1992.

CARR, M. Model confusion in chemistry, Research in Science Education, n. 14, p. 97-103, 1984.

CROS, D.; MAURIN, M.; AMOUROUX, R.; CHASTRETTE, M.; LEBER, J. e FAYOL, M. Conceptions of first-year university students of the constituents of matter and the notions of acids and bases. European Journal of Science Education, v. 8, n. 3, p. 305-13, 1986.

GILBERT e BOULTER, 1998.

GOODMAN, D. e RUSSEL, C.A. The Rise of Scientific Europe 1500-1800 Hodder e Stoughton, Londres, 1991.

HAND, B.M. e TRESGUST, D.F. Application of a conceptual conflict teaching strategy to enhance student learning of acids and bases. Research in Science Education, n. 18, p. 53-63, 1998.

HAND, B. Student understanding of acids and bases: a two year study. Research in Science Education, n. 19, p. 133-44, 1989.

ROSS, B. e MUNBY, H. (1991), Concept mapping and misconceptions: a study of high-school students understandings of acids and bases. International Journal of Science Education, v. 13, n. 1, 11-23.

SCHMIDT, H-J. (1991) A label as a hidden persuader: chemists' neutralisation concept. International Journal of Science Education, v. 13, n. 4, p. 459-471.

ACHMIDT, J-J. (1995) applying the concept of conjugation to the Brönsted theory of acid-base reactions by senior high school students from Germany. International Journal of Science Education.

\section{Notas do tradutor}

1. Cursos "A Levels" ou "Advanced Levels" correspondem a cursos semelhantes ao ensino médio no Brasil. Tais cursos são preparatórios para exames de seleção para o acesso a níveis de estudo superiores ou universitários.

2. Nuffield é o nome de um dos cursos "A Levels" no Reino Unido.

3. Os livros são divididos em três áreas da química: físico-química, química inorgânica e química orgânica. 
OVERSBY, J. Uma análise dos livros didáticos no ensino... 